\title{
The structural properties of boron and nitrogen adsorption on benzene molecule: a density functional study
}

\author{
Samaneh S. Hoseini • Edris Faizabadi
}

Received: 12 November 2014/Accepted: 7 January 2015/Published online: 23 January 2015

(C) The Author(s) 2015. This article is published with open access at Springerlink.com

\begin{abstract}
The structural properties of boron and nitrogen atoms added on benzene $(\mathrm{Bz})$ molecule are studied using density functional theory within Gaussian 03 program package. The adsorption energy, HOMO-LUMO energy gap $\left(\Delta_{\mathrm{H}-\mathrm{L}}\right)$ and also the optimized bond lengths $(\mathrm{C}-\mathrm{C}$ and $\mathrm{C}-\mathrm{H}$ bond lengths) of the structures are evaluated. In this work, three adsorption sites for both boron and nitrogen were selected, hollow site (H), middle site (M) and top site (T), as their initial positions. It is found that for boron adsorption on $\mathrm{Bz}$ molecule, the relaxed middle site configuration has the most stable geometry, while in NBz, we obtained similar positions after optimization process. We have also illustrated that the relaxed $\mathrm{NBz}$ positions are in higher stability than the relaxed $\mathrm{BBz}$ positions. As a consequence, it is found that the stability of an isolated benzene molecule increases by adding boron or nitrogen on top of it.
\end{abstract}

Keywords Density functional theory .

Electronic structure - Configuration · Adsorption energy · HOMO-LUMO energy gap · Optimized bond length

\section{Introduction}

Benzene, one of the organic molecules, because of its special properties has long been on the focus of both theoretical and experimental research. In chemical studies, benzene is used as a useful substance including as a solvent or also as a precursor of many synthetic materials, and so

S. S. Hoseini $(\bowtie) \cdot$ E. Faizabadi

School of Physics, Iran University of Science and Technology,

Tehran 16846, Iran

e-mail: s.s.hoseini2288@gmail.com on [1]. While some works studied mono-benzene or multibenzene molecules solely [2, 3], yet others considered benzene rings with hetero-atoms or hetero-molecules [4, 5]. Among all hetero-atoms, we have selected boron and nitrogen as two atoms on both sides of carbon atom in periodic table with difference of one electron less and more than the number of valence electrons in carbon, respectively. Some experimental and theoretical studies were performed on benzene with boron and nitrogen atoms. Kostic et al. [6] have theoretically studied borabenzene anion $\left(\mathrm{BBz}^{-}\right)$and its sandwich complexes $\left[(\mathrm{BBz})_{2} \mathrm{Fe}\right.$ and $\left.(\mathrm{BBz})_{2} \mathrm{Co}\right]$ to obtain their bonding, electronic structure and substitution reactions properties. A quantum mechanical $\mathrm{ab}$ initio calculations of benzene- $\mathrm{BX} \mathrm{X}_{3}(\mathrm{X}=\mathrm{H}, \mathrm{F}, \mathrm{Cl})$ interaction at the level of $\mathrm{Mp} 2 / 6-311++\mathrm{G}^{* *}$, was performed by Tarakeshwar et al. [7]. They also carried out some singlepoint calculations at a much higher level of correlation with larger basis set (MP4/6-311++G(2df,p) + diffuse(d,p)). Their binding energy calculations suggest that all of these complexes have weakly bound van der Waals and the weakest one is for benzene- $\mathrm{BF}_{3}$. Another investigation on boron with benzene was carried out by Zhang et al. [8]. In their experimental work, the reactions of ground-state were studied using the crossed molecular beam technique. Venturo et al. [9] have done some theoretical calculations on neutral solute-(solvent) ${ }_{n}$ clusters for the benzene- $\left(\mathrm{N}_{2}\right)_{n}$ case, where $n=1-32$. The size evolution of $\mathrm{N}_{2}$ in benzene- $\left(\mathrm{N}_{2}\right)$ clusters was measured by massselective ionization-loss stimulated Raman spectroscopy in this experimental work. A theoretical study on the complexes of benzene with isoelectronic nitrogen was performed by Wang et al. [10] at the MP2 and DFT-SAPT calculations. They have calculated the $\mathrm{C}-\mathrm{H}$ bond length and binding energies and have found that all energy components increase with the number of nitrogen atoms. 
Srivastava et al. [11] have investigated the influence of adding boron and nitrogen to benzene as impurities instead of the last carbon atom or the last hydrogen atom. They have analyzed their data based on single electron transition (SET) using density functional theory. Their calculations have indicated that at zero gate potential in SET environment, $\mathrm{C}_{5} \mathrm{H}_{6} \mathrm{~N}$ has more stability in its positively charged state, whereas $\mathrm{C}_{6} \mathrm{H}_{6}, \mathrm{C}_{5} \mathrm{H}_{6} \mathrm{~B}$ and $\mathrm{C}_{6} \mathrm{H}_{5} \mathrm{~N}$ are more stable in their neutral state. Besides, $\mathrm{C}_{6} \mathrm{H}_{5} \mathrm{~B}$ shows more stability in both neutral and positively charged states.

In this work, we have theoretically investigated the stable positions of benzene with boron $(\mathrm{BBz})$ and with nitrogen $(\mathrm{NBz})$ using density functional theory with the Gaussian 03 program package. In addition, the adsorption energies, HOMO-LUMO gaps and optimized bond lengths have been evaluated.

The paper is organized as follows; in the next section the method and numerical approach are presented. In "Results and Discussion", we have discussed our results. Finally, we end the paper with a brief conclusion.

\section{Methods}

All of our electronic structure calculations in this work were carried out using density functional theory (DFT) [12] within Gaussian 03 program package [13]. The selected structures of adsorbing boron and nitrogen on benzene were fully optimized at the B3LYP [14, 15] level using $6-31++\mathrm{G}(\mathrm{d}, \mathrm{p})$ basis set. In the present work for both boron and nitrogen three adsorption sites were selected, namely hollow site (H), middle site (M) and top site (T) as initial geometric configurations which can be seen in Fig. 1. The most stable structures and optimized bond lengths have been obtained via optimizing these positions. Moreover, the highest occupied and lowest unoccupied molecular orbital (HOMO and LUMO) energy gaps and the adsorption energies $\left(E_{\text {ads }}\right)\left\{E_{\text {ads }}=E_{\mathrm{Bz}}+E_{\text {adatom }}-E_{\text {complex }}\right\}$ have been calculated, where $E_{\mathrm{Bz}}$ and $E_{\text {adatom }}$ are the energy of the isolated benzene and adatom, respectively, and $E_{\text {complex }}$ is the energy of the fully relaxed benzene with adatom.

\section{Results and discussion}

It should be mentioned that the position of relaxed structure depends on its initial geometric configuration. Thus if we change the primary configuration, we could obtain another final position. We discuss the results as follows;

\section{Boron on benzene}

As it is clear in Figs. 1 and 2, all of the initial structures are deformed after optimization process. In hollow site position we have a curved benzene molecule with a boron atom on top of it, whereas in middle site case the boron atom with benzene molecule has formed a flat stable structure. In the third position an approximately plane benzene molecule with a boron atom on it can be seen. According to our calculations the structure with middle site initial configuration has the maximum value of adsorption energy, so it is the most stable structure. Another important quantity that was investigated in this work is HOMO-LUMO energy gap $\left(\Delta_{\mathrm{H}-\mathrm{L}}\right)$ as an indicator of chemical reactivity for a structure, in which a larger $\Delta_{\mathrm{H}-\mathrm{L}}$ means less reactivity. It must be noted that, the most sustainable structure in this process has minimum $\Delta_{\mathrm{H}-\mathrm{L}}$ and so maximum chemical reactivity. Our results are shown in Table 1 .

Comparing the results of boron on benzene molecule with an isolated benzene (see Table 1) shows that the isolated benzene is less stable than complex forms with lower chemical reactivity. The optimized bond lengths are shown in Table 2. By comparing the results of these structures with an isolated benzene molecule after
Fig. 1 The initial positions of adsorbing $\mathrm{X}(\mathrm{X}=\mathrm{B}, \mathrm{N})$ on benzene molecule

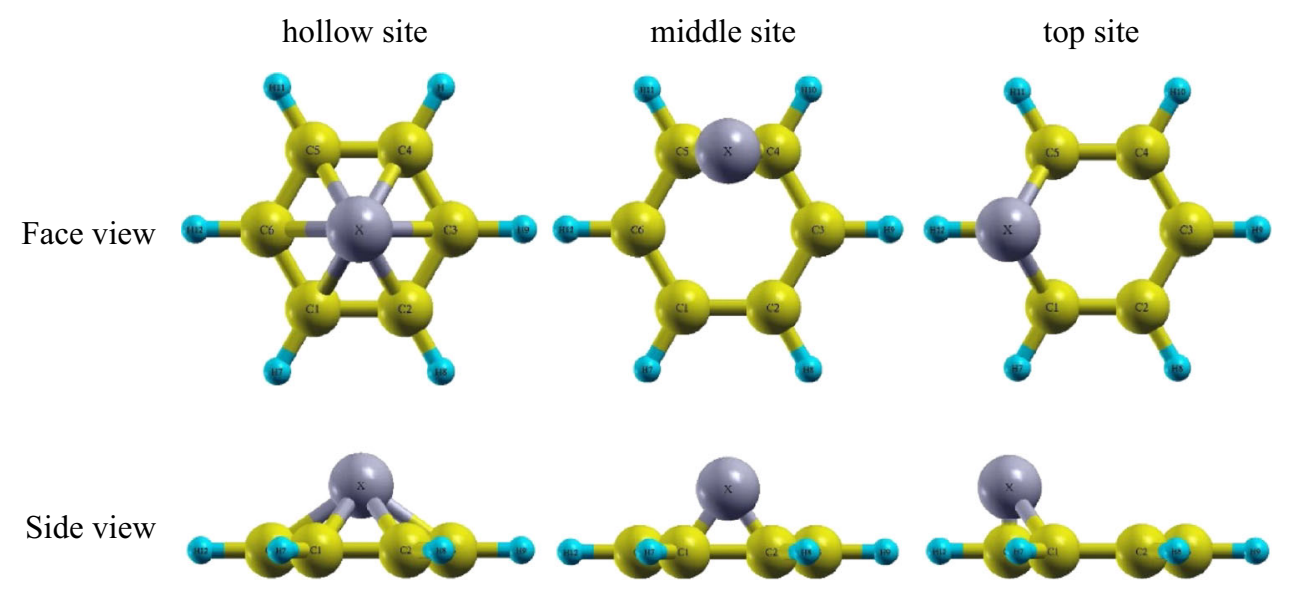


Fig. 2 The relaxed structures of adsorbing a boron atom on benzene molecule
Face view
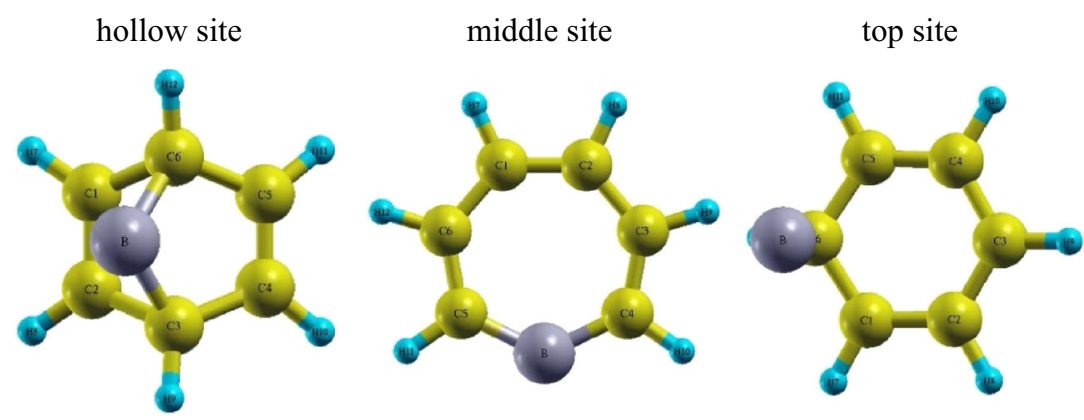

Side view

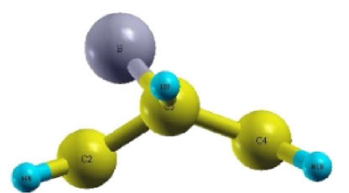

top site

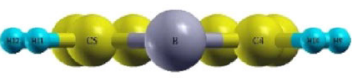

Table 1 The total energies $\left(E_{\mathrm{t}}\right)$, the adsorption energies $\left(E_{\text {ads }}\right)$ and the HOMO-LUMO gaps $\left(\Delta_{\mathrm{H}-\mathrm{L}}\right)$ for all of the relaxed structures

\begin{tabular}{llll}
\hline & $E_{\mathrm{t}}$ & $E_{\mathrm{ads}}$ & $\Delta_{\mathrm{H}-\mathrm{L}}$ \\
\hline $\mathrm{Bz}$ & $-6,320.3494$ & - & 0.242 \\
$\mathrm{BBz}(\mathrm{H})$ & $-6,992.8105$ & 1.440 & 0.172 \\
$\mathrm{BBz}(\mathrm{M})$ & $-6,993.8674$ & 2.497 & 0.083 \\
$\mathrm{BBz}(\mathrm{T})$ & $-6,991.7476$ & 0.377 & 0.103 \\
$\mathrm{NBz}(\mathrm{H})$ & $-7,806.8440$ & 3.864 & 0.185 \\
$\mathrm{NBz}(\mathrm{M})$ & $-7,806.8440$ & 3.864 & 0.185 \\
$\mathrm{NBz}(\mathrm{T})$ & $-7,806.8440$ & 3.864 & 0.184 \\
\hline
\end{tabular}

The energies are in $(\mathrm{eV})$

optimization process, it may be concluded that the $\mathrm{C}-\mathrm{H}$ bond lengths are approximately similar, whereas some of the $\mathrm{C}-\mathrm{C}$ bond lengths are different from the value in an isolated benzene which is approximately $1.398 \AA$. Based on our calculations, the difference between the maximum $\mathrm{C}-\mathrm{C}$ bond length in complex structures and the $\mathrm{C}-\mathrm{C}$ bond length in the isolated benzene is $0.104 \AA$.
Nitrogen on benzene

As it is shown in Fig. 3 the optimized positions are almost similar to each other, so there is no significant difference between their $E_{\mathrm{ads}}$ and $\Delta_{\mathrm{H}-\mathrm{L}}$ values. The results are shown in Table 1. Similar to previous stage the isolated relaxed benzene molecule, because of its absolute value of energy, is more unstable and has less chemical reactivity (see Table 1). As it is evident in Table 2, the optimized bond lengths are similar in these three relaxed complex structures and only slight difference is observable. Our finding shows that the $\mathrm{C}-\mathrm{H}$ bond lengths in complex forms are approximately similar to those in the isolated benzene after optimization process. Whereas the $\mathrm{C}-\mathrm{C}$ bond lengths are changed and their maximum value is $1.539 \AA$.

Finally, as a comparative study on adsorption energies between $\mathrm{BBz}$ and $\mathrm{NBz}$, we have found that the $\mathrm{NBz}$ is more stable than $\mathrm{BBz}$ in per position, whereas the chemical reactivity of $\mathrm{BBz}$ is higher than $\mathrm{NBz}$. Therefore, as a consequence, our calculation indicates that we can obtain
Table 2 The optimized bond lengths of the relaxed structures

The bond lengths are in $\AA$

\begin{tabular}{llllllll}
\hline & $\mathrm{Bz}$ & $\mathrm{BBz}(\mathrm{H})$ & $\mathrm{BBz}(\mathrm{M})$ & $\mathrm{BBz}(\mathrm{T})$ & $\mathrm{NBz}(\mathrm{H})$ & $\mathrm{NBz}(\mathrm{M})$ & $\mathrm{NBz}(\mathrm{T})$ \\
\hline $\mathrm{C}_{1}-\mathrm{C}_{2}$ & 1.398 & 1.384 & 1.379 & 1.377 & 1.472 & 1.451 & 1.473 \\
$\mathrm{C}_{2}-\mathrm{C}_{3}$ & 1.398 & 1.501 & 1.426 & 1.416 & 1.539 & 1.355 & 1.355 \\
$\mathrm{C}_{3}-\mathrm{C}_{4}$ & 1.398 & 1.501 & 1.380 & 1.417 & 1.472 & 1.473 & 1.452 \\
$\mathrm{C}_{4}-\mathrm{C}_{5}$ & 1.398 & 1.343 & - & 1.376 & 1.355 & 1.539 & 1.355 \\
$\mathrm{C}_{5}-\mathrm{C}_{6}$ & 1.398 & 1.502 & 1.380 & 1.492 & 1.451 & 1.473 & 1.472 \\
$\mathrm{C}_{6}-\mathrm{C}_{1}$ & 1.398 & 1.500 & 1.426 & 1.493 & 1.355 & 1.355 & 1.539 \\
$\mathrm{C}_{1}-\mathrm{H}_{7}$ & 1.086 & 1.085 & 1.089 & 1.085 & 1.086 & 1.086 & 1.090 \\
$\mathrm{C}_{2}-\mathrm{H}_{8}$ & 1.086 & 1.085 & 1.089 & 1.087 & 1.090 & 1.086 & 1.086 \\
$\mathrm{C}_{3}-\mathrm{H}_{9}$ & 1.086 & 1.086 & 1.092 & 1.084 & 1.090 & 1.086 & 1.086 \\
$\mathrm{C}_{4}-\mathrm{H}_{10}$ & 1.086 & 1.086 & 1.091 & 1.087 & 1.086 & 1.090 & 1.086 \\
$\mathrm{C}_{5}-\mathrm{H}_{11}$ & 1.086 & 1.086 & 1.091 & 1.085 & 1.086 & 1.090 & 1.086 \\
$\mathrm{C}_{6}-\mathrm{H}_{12}$ & 1.086 & 1.086 & 1.092 & 1.097 & 1.086 & 1.086 & 1.090 \\
\hline
\end{tabular}


Fig. 3 The relaxed structures of adsorbing a nitrogen atom on benzene molecule
Face view
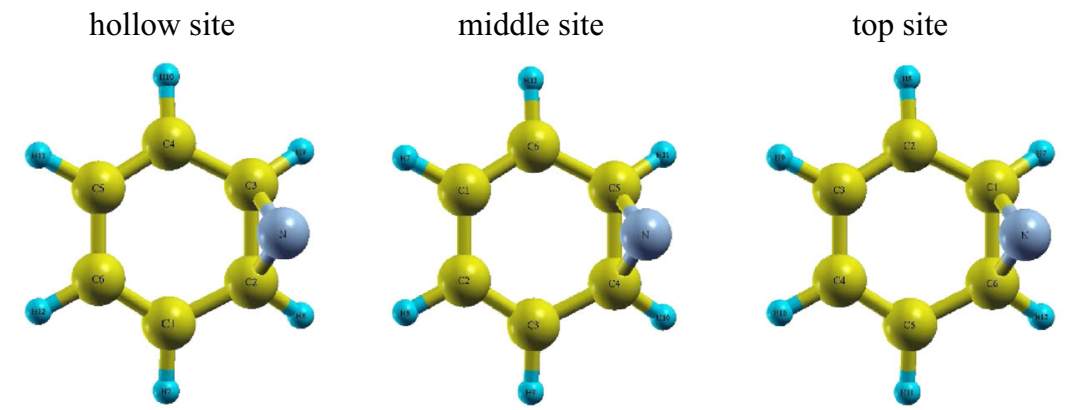

Side view
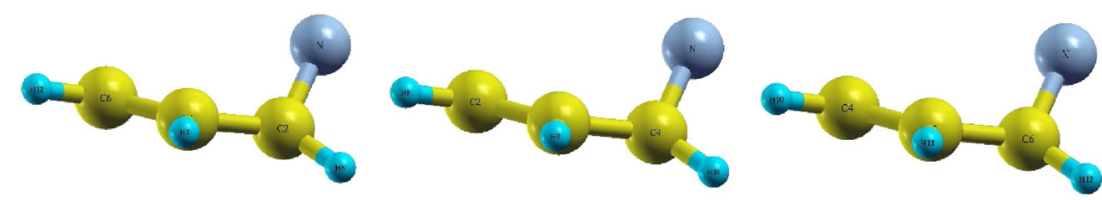

more stable structures by adsorbing nitrogen atom on a benzene molecule.

\section{Conclusions}

We studied the structural properties of adsorbing boron and nitrogen atoms on benzene molecule in three site positions using density functional theory method at the level of B3LYP/6-31++G(d, p). Via optimization process, the stable geometrical structures and optimized bond lengths have been obtained. We have investigated the most stable structures and their chemical reactivity by calculating the adsorption energies and HOMO-LUMO energy gaps, respectively. According to our results, the relaxed middle site position in the case of adsorbing boron atom is the most stable structure, whereas we obtained three similar configurations by relaxing the case of adsorbing nitrogen atom. Comparing these two groups of structures, we found that the NBz structures with higher adsorption energies are more stable, however, they are in less chemically reactive. Finally, we have realized that by adding boron and nitrogen, we are able to obtain the structures with more stability and chemical reactivity compared to isolated benzene.

Acknowledgments This work was supported by Iran University of Science and Technology Grant.

Open Access This article is distributed under the terms of the Creative Commons Attribution License which permits any use, distribution, and reproduction in any medium, provided the original author(s) and the source are credited.

\section{References}

1. Foo, S.C.: Benzene pollution from gasoline usage. Sci. Total Environ. 103, 19-26 (1991)
2. Pavone, M., Rega, N., Barone, V.: Implementation and validation of DFT-D for molecular vibrations and dynamics: the benzene dimer as a case study. Chem. Phys. Lett. 452, 333-339 (2008)

3. Bludský, O., Rubeš, M., Soldán, P., Nachtigall, P.: Investigation of the benzene-dimer potential energy surface: DFT/ CCSD(T) correction scheme. J. Chem. Phys. 128, 114102 (2008)

4. Rungsirisakun, R., Jansang, B., Pantu, P., Limtrakul, J.: The adsorption of benzene on industrially important nanostructured catalysts (H-BEA, H-ZSM-5, and H-FAU): confinement effects. J. Mol. Struct. 733, 239-246 (2005)

5. Hansen, N., Kerber, T., Sauer, J., Bell, A.T., Keil, F.J.: Quantum chemical modeling of benzene ethylation over H-ZSM-5 approaching chemical accuracy: a hybrid MP2:DFT study. J. Am. Chem. Soc. 132, 11525-11538 (2010)

6. Kostić, N.M., Fenske, R.F.: Molecular orbital study of bonding, structure, and substitution reactions of Bis(borabenzene)iron. Organometallics 2, 1319-1325 (1983)

7. Tarakeshwar, P., Lee, S.J., Lee, J.Y., Kim, K.S.: Ab initio study of benzene- $\mathrm{BX}_{3}(\mathrm{X}=\mathrm{H}, \mathrm{F}, \mathrm{Cl})$ interactions. J. Phys. Chem. B. 103, 184-191 (1999)

8. Zhang, F., Guo, Y., Gu, X., Kaiser, R.I.: A crossed molecular beam study on the reaction of boron atoms, $\mathrm{B}\left({ }^{2} \mathrm{P}_{\mathrm{j}}\right)$, with benzene, $\mathrm{C}_{6} \mathrm{H}_{6}\left(\mathrm{X}^{1} \mathrm{~A}_{1 \mathrm{~g}}\right)$, and D6-benzene $\mathrm{C}_{6} \mathrm{D}_{6}\left(\mathrm{X}^{1} \mathrm{~A}_{1 \mathrm{~g}}\right)$. Chem. Phys. Lett. 440, 56-63 (2007)

9. Venturo, V.A., Maxton, P.M., Felker, P.M.: Size evolution of solvent vibrational structure in neutral solute-(solvent) $)_{\mathrm{n}}$ clusters: benzene- $\left(\mathrm{N}_{2}\right)_{\mathrm{n}}, \mathrm{n}=1-32$. J. Phys. Chem. 96, 5234-5237 (1992)

10. Wang, W., Hobza, P.: Theoretical study on the complexes of benzene with isoelectronic nitrogen-containing heterocycles. ChemPhysChem 9, 1003-1009 (2008)

11. Srivastava, A., Santhibhushan, B., Dobwal, P.: Performance analysis of impurity added benzene based single-electron transistor. Appl. Nanosci. 4, 263-269 (2014)

12. Hohenberg, P., Kohn, W.: Inhomogeneous electron gas. Phys. Rev. B. 136, 864 (1964)

13. Foresman, J.B., Frisch, A.: Exploring chemistry with electronic structure methods. Gaussian Inc., Wallingford (1996)

14. Becke, A.D.: Density-functional thermochemistry. III. The role of exact exchange. J. Chem. Phys. 98, 5648 (1993)

15. Lee, C., Yang, W., Parr, R.G.: Development of the Colle-Salvetti correlation-energy formula into a functional of the electron density. Phys. Rev. B. 37, 785 (1988) 